\title{
Penerapan Metode Dual Stack, Metode Tunneling dan Metode Translation dalam Transisi IPv4/IPv6 Untuk Pembelajaran Jaringan Komputer
}

\author{
Joshua Marthen Manuputty ${ }^{1}$, Hartanto K. Wardana², Saptadi Nugroho ${ }^{3}$ \\ Program Studi Sistem Komputer, \\ Fakultas Teknik Elektronika dan Komputer, \\ Universitas Kristen Satya Wacana, Salatiga \\ 1joshua.m.manuputty@gmail.com, 2hartanto.kusuma @staff.uksw.edu, \\ ${ }^{3}$ saptadi_nugroho@yahoo.com
}

\begin{abstract}
Ringkasan
Perkembangan dari teknologi IPv6 dimasa sekarang dibuat untuk menggantikan teknologi IPv4 yang memiliki keterbatasan dalam beberapa aspek, karena itulah diperlukannya suatu pedoman yang dapat membantu mahasiswa untuk mempelajari lebih lanjut mengenai teknologi ini. Penulisan ini bertujuan untuk menghasilkan pedoman praktikum yang akan digunakan pada matakuliah jaringan komputer. Penulisan ini juga berisi tentang analisa penerapan beberapa metode transisi dari IPv4 ke IPv6, yaitu metode dual stack, tunneling, dan translation. Analisa dari metode - metode yang ada akan melihat uji konektivitas antar perangkat, serta penjelasan mengenai informasi paket data yang dikirimkan antar perangkat.
\end{abstract}

Kata kunci: IPv4, IPv6, Dual Stack, Tunneling, Translation

\section{Pendahuluan}

Dewasa ini, salah satu teknologi yang diterapkan pada suatu jaringan adalah IPv4 atau Internet Protocol Version 4. Salah satu penerapan dari teknologi IPv4 pada suatu jaringan yaitu menjadi standar yang mengatur proses komunikasi. Namun dengan semakin cepatnya perkembangan internet secara eksponensial, maka mengakibatkan munculnya beberapa hal yang mempengaruhi implementasi dari IPv4, yaitu seperti adanya keterbatasan ruang alamat yang ditawarkan IPv4 pada jaringan di seluruh dunia, tuntutan atas konfigurasi yang lebih sederhana, tuntutan keamanan pada tingkat Internet Protocol (IP), dan lain sebagainya. Untuk menanggulangi berbagai macam keterbatasan pada penerapan IPv4, maka pada tahun 1994, sebuah organisasi internasional, yaitu Internet Engineering Task Force (IETF) mulai mengembangkan berbagai standar dan suite protocol IPv6 sebagai penerus IPv4 [5]. IPv6 Working Group yang merupakan bagian dari IETF diresmikan sebagai grup kerja yang fokus untuk mengembangkan IPv6 dan memulainya dengan proyek bernama WIDE, hingga akhirnya atas berbagai usaha bersama dari berbagai partisipan, seperti 6Bone, Next Generation Transition Working Group, 6ren, IPv6 Forum telah menghasilkan teknologi IPv6. Dengan sejumlah kelebihan yang ada pada IPv6 telah disosialisasikan yang dimulai dari lingkungan penyedia layanan 
akses internet, yaitu ISP (Internet Service Provider). Para pengguna tentu memerlukan pengalamatan di dalam jaringan komputer untuk komputer dan perangkat lainnya yang saling terhubung, sehingga diperlukannya proses migrasi dari IPv4 ke IPv6. Terdapat berbagai teknik yang dapat digunakan untuk melakukan proses migrasi dari IPv4 to IPv6, antara lain IPinIP, GRE (Generic Routing Encapsulation), 6to4, Teredo, ISATAP (Intra Site Automatic Tunnel Addressing Protocol), MPLS (MultiProtocol Label Switching), dan lain sebagainya [2].

\section{Metode Transisi dari IPv4 Menuju IPv6}

Dilakukannya pengujian terhadap tiga metode transisi dari IPv4 menuju IPv6 berupa langkah - langkah pembelajaran di laboratorium, yaitu metode dual stack, tunneling, dan translation. Penjelasan dari masing - masing metode sebagai berikut:

a. Metode Dual Stack

Dalam sebuah jaringan dual stack, host dan router mengimplementasikan protokol IPv4 dan IPv6. Gambar 1 menunjukkan bagaimana proses jaringan yang dapat mendukung layanan IPv4 dan IPv6.

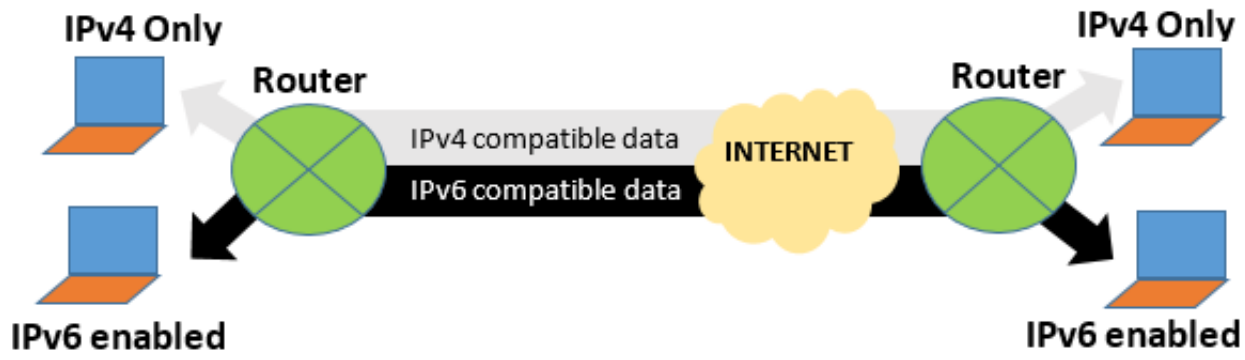

Gambar 1. Metode Dual Stack [4]

b. Metode Tunneling

Tunneling memungkinkan jaringan IPv6 yang terpisah untuk berkomunikasi melalui jaringan IPv4. Cara kerja dari salah satu jenis metode tunneling yang mana paket data dengan protokol IPv6 dienkapsulasi oleh router, kemudian paket data dikirim melalui jaringan IPv4 dan diterjemahkan oleh router pada jaringan IPv6 penerima. Gambar 2 menunjukkan proses tunneling IPv6 dalam sebuah jaringan IPv4.

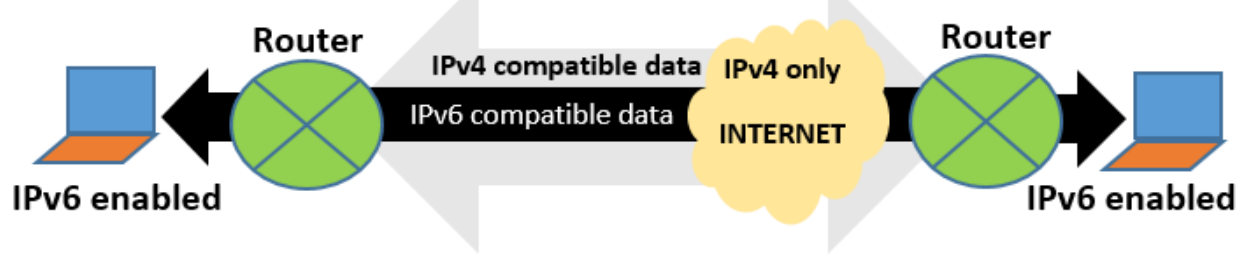

Gambar 2. Metode Tunneling [4]

c. Metode Translation

Pada jaringan translation, perangkat IPv4 dan IPv6 dapat saling berkomunikasi dalam satu jaringan yang sama. Hal ini dimungkinkan dengan adanya proses translasi paket IPv6 menjadi paket IPv4. Meskipun metode ini dapat diterapkan 
Penerapan Metode Dual Stack, Metode Tunneling dan Metode Translation dalam

Transisi IPv4/IPv6 Untuk Pembelajaran Jaringan Komputer Joshua Marthen Manuputty, Hartanto K. Wardana, Saptadi Nugroho

antar perangkat yang berbeda protocol [4]. Gambar 3 menunjukkan proses translation IPv6.

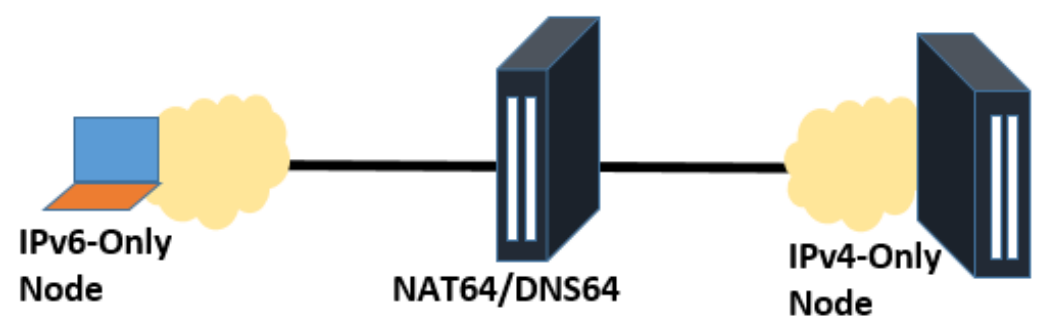

Gambar 3. Metode Translation [1]

Jaringan - jaringan yang dibuat sebagai bentuk penerapan dari ketiga metode tersebut dilakukan menggunakan program GNS3 yang diintegrasikan dengan program virtualbox, sedangkan untuk melihat konektivitas jaringan menggunakan program ping. Adapun dalam pemantauan informasi tiap paket data selama proses pengiriman menggunakan program wireshark.

\section{1. $\quad$ Metode Dual Stack}

Model jaringan dual stack yang dirancang seperti yang ditunjukkan pada Gambar 4 dan Gambar 5, dimana terdapat dua protokol IP yang berbeda, yaitu IPv4 dan IPv6 dalam satu jaringan yang sama. Perangkat yang digunakan terdapat dua router cisco 7200 , empat VPCS (Virtual Personal Computer Simulator) yang dapat diganti dengan host virtualbox.

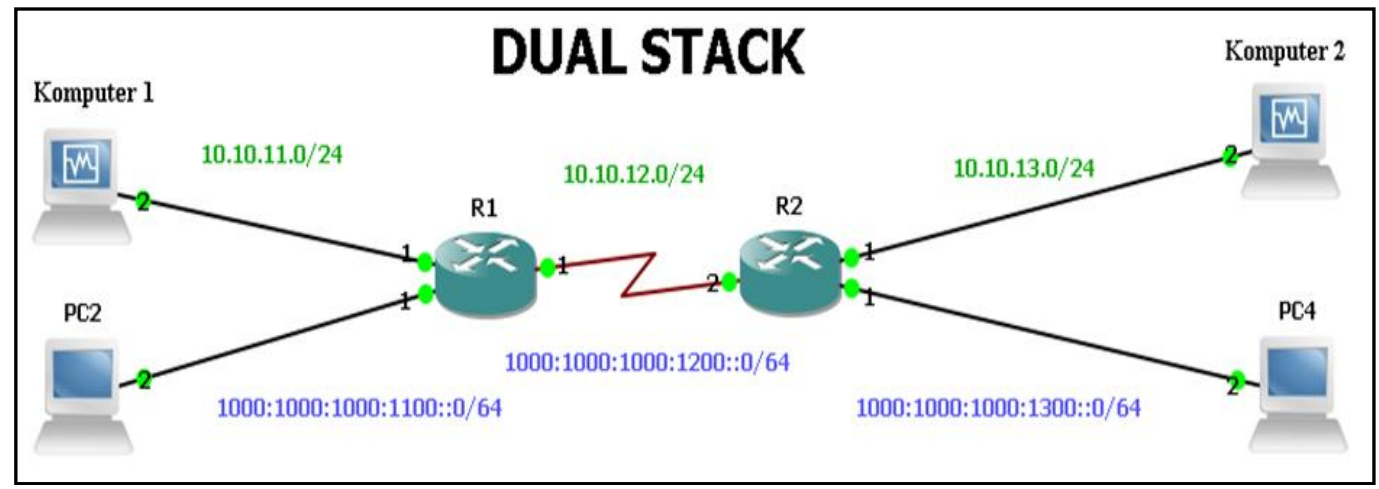

Gambar 4. Jaringan Dual Stack IPv4

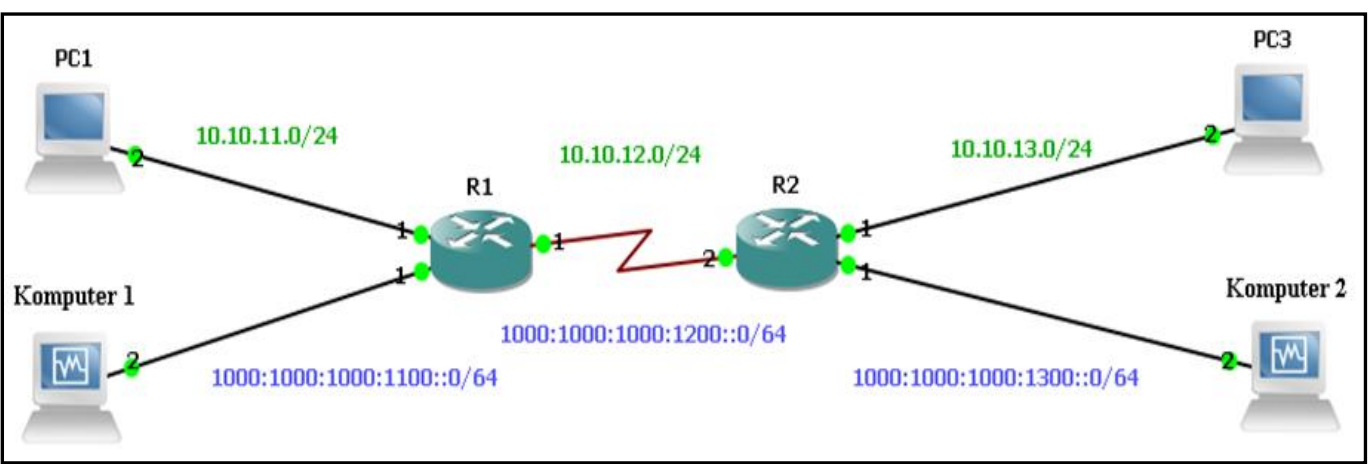

Gambar 5. Jaringan Dual Stack IPv6 


\subsubsection{Hasil Uji Koneksi}

Hasil pengujian seperti pada Tabel 1 untuk protokol IPv4, sedangkan pada Tabel 2 untuk pengujian dengan protokol IPv6. Dari tiga kali pengujian didapat jeda waktu pengiriman paket data ICMP sebesar 50 byte dengan protokol IPv4 adalah selama 33,3 ms dan jeda waktu pengiriman paket data ICMPv6 sebesar 50 byte dengan protokol IPv6 adalah selama $37 \mathrm{~ms}$.

Tabel 1. Hasil ping Komputer 1 Menuju Komputer 2

\begin{tabular}{|c|c|c|c|}
\hline \multicolumn{4}{|c|}{ Komputer 1 IPv4 } \\
\hline Paket & Waktu 1 (ms) & Waktu 2 (ms) & Waktu 3 (ms) \\
\hline 1 & 41 & 42 & 42 \\
\hline 2 & 40 & 36 & 36 \\
\hline 3 & 25 & 26 & 26 \\
\hline 4 & 25 & 38 & 38 \\
\hline Median & 32 & 35 & 33 \\
\hline
\end{tabular}

Tabel 2. Hasil ping Komputer 1 Menuju Komputer 2

\begin{tabular}{|c|c|c|c|}
\hline \multicolumn{4}{|c|}{ Komputer 1 IPv6 } \\
\hline Paket & Waktu 1 (ms) & Waktu 2 (ms) & Waktu 3 (ms) \\
\hline 1 & 41 & 40 & 40 \\
\hline 2 & 37 & 41 & 35 \\
\hline 3 & 35 & 33 & 41 \\
\hline 4 & 35 & 38 & 31 \\
\hline Median & 37 & 38 & 36 \\
\hline
\end{tabular}

\subsubsection{Informasi Paket Data}

Dari hasil percobaan, ukuran paket data ICMP sebesar 92 byte, sedangkan pada proses ping yang dilakukan mengirimkan file ICMP sebesar 50 byte. Keterangan dari paket data dengan protokol IPv4, yaitu paket data ethernet II berisi data mengenai alamat tujuan dan alamat sumber. Paket data ini berukuran 14 byte, dengan masing - masing paket sebesar 6 byte, paket data IPv4 memuat berbagai bagian, seperti halnya version, header length, protocol, dan lain sebagainya. Pada paket data ini berukuran 20 byte, dan paket data ICMP berukuran 58 byte. 8 byte memuat informasi mengenai protokol ICMP, yaitu type, code, checksum, dan lain sebagainya, serta adanya tambahan data yang berukuran 50 byte.

Paket data IPv6 berukuran 40 byte, paket data ini terdiri dari beberapa bagian, seperti version, traffic class, payload length, next header, dan lain sebagainya, dan paket data ICMPv6 berukuran 58 byte. Paket data ini terdiri dari 8 byte yang memuat informasi mengenai protokol ICMv6, yaitu type, code, checksum, dan lain sebagainya, serta 50 byte yang memuat file yang berukuran 50 byte. Dengan seluruh data yang ada telah menunjukkan bahwa metode dual stack memungkinkan agar dua protokol, yaitu IPv4 dan IPv6 untuk dapat tetap terkoneksi dalam satu jaringan yang sama, meskipun tanpa adanya perubahan dari isi paket data yang dikirimkan.

\subsection{Metode Tunneling}

Model jaringan tunneling yang dirancang seperti yang ditunjukkan pada Gambar 6 . Perangkat yang digunakan terdapat dua router cisco 7200, dua VPCS (Virtual Personal Computer Simulator) yang dapat diganti dengan host virtualbox. 
Penerapan Metode Dual Stack, Metode Tunneling dan Metode Translation dalam

Transisi IPv4/IPv6 Untuk Pembelajaran Jaringan Komputer Joshua Marthen Manuputty, Hartanto K. Wardana, Saptadi Nugroho

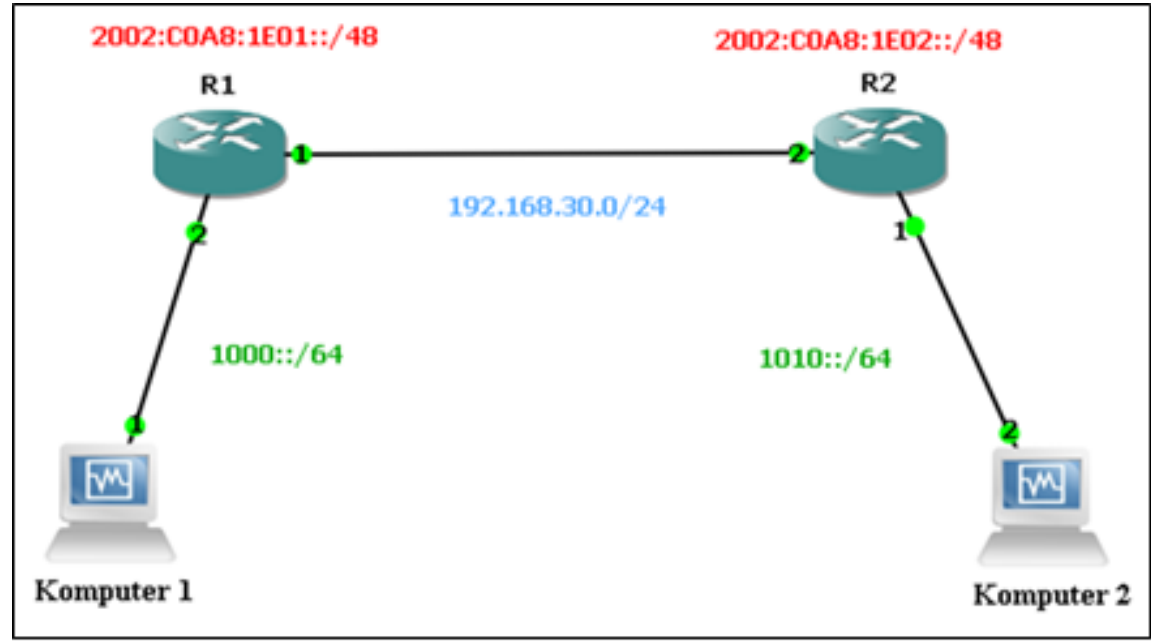

Gambar 6. Jaringan Dual Stack IPv6

\subsubsection{Hasil Uji Koneksi}

Hasil pengujian menggunakan perintah ping seperti pada Tabel 3 untuk pengujian dengan protokol IPv6. Dari tiga kali pengujian didapat jeda waktu rata - rata pengiriman paket data ICMPv6 sebesar 50 bytes selama 303 ms.

Tabel 3. Hasil ping Komputer 1 Menuju Komputer 2

\begin{tabular}{|c|c|c|c|}
\hline \multicolumn{4}{|c|}{ Komputer 1 IPv6 } \\
\hline Paket & Waktu 1 $(\mathrm{ms})$ & Waktu 2 $(\mathrm{ms})$ & Waktu 3 $(\mathrm{ms})$ \\
\hline 1 & 36 & 728 & 22 \\
\hline 2 & 1516 & 806 & 40 \\
\hline 3 & 43 & 30 & 235 \\
\hline 4 & 135 & 23 & 25 \\
\hline Median & 432 & 396 & 80 \\
\hline
\end{tabular}

\subsubsection{Informasi Paket Data}

Paket data yang dikirimkan dari Komputer 1 memiliki ukuran total 112 byte dengan format paket data IPv6 secara umum, tetapi pada paket data yang diterima oleh router, terlihat adanya penambahan protokol IPv4 sebesar 20 byte. Pada Tabel 4 menunjukkan bahwa paket data ICMPv6 dari Komputer 1 (1000:1) memang ditujukan kepada Komputer 2 (1010::2), namun dikarenakan akan melewati jaringan IPv4, maka adanya penambahan protokol IPv4 pada paket data sehingga paket data dapat melalui jaringan IPv4. Pengaturan ini dilakukan pada interface tunnel 0 yang menghubungkan antara R1 dengan alamat 2002:C0A8:1E01::/48 dan R2 dengan alamat 2002:C0A8:1E02::/48. Setelah paket data ICMPv6 telah ditambahkan protokol IPv4, maka paket data tersebut dikirimkan melalui jaringan IPv4 dari R1 dengan alamat 192.168.30.1 menuju R2 dengan alamat 192.168.30.2. 
Tabel 4. Beberapa Perbedaan Antara Paket Data Komputer 1 dan R1

\begin{tabular}{|l|c|}
\hline \multicolumn{2}{|c|}{ Paket Data Pada Komputer 1 } \\
\hline Device & Komputer 1 \\
\hline Version & IPv6 \\
\hline Source & 1000::99da:6746:21fc:22c1 \\
\hline Destination & 1010::2 \\
\hline \multicolumn{2}{|c|}{ Paket Data Pada R1 } \\
\hline Device & IPv4 \\
\hline Version & 192.168 .30 .1 \\
\hline Source & 192.168 .30 .2 \\
\hline Destination & IPv6 \\
\hline Version & $1000:: 99$ da:6746:21fc:22c1 \\
\hline Source & $1010: 2$ \\
\hline Destination &
\end{tabular}

\subsection{Metode Translation}

Model jaringan translation yang dirancang seperti yang ditunjukkan pada Gambar 11, dimana perangkat yang digunakan pada jaringan berupa lima router cisco 3725.

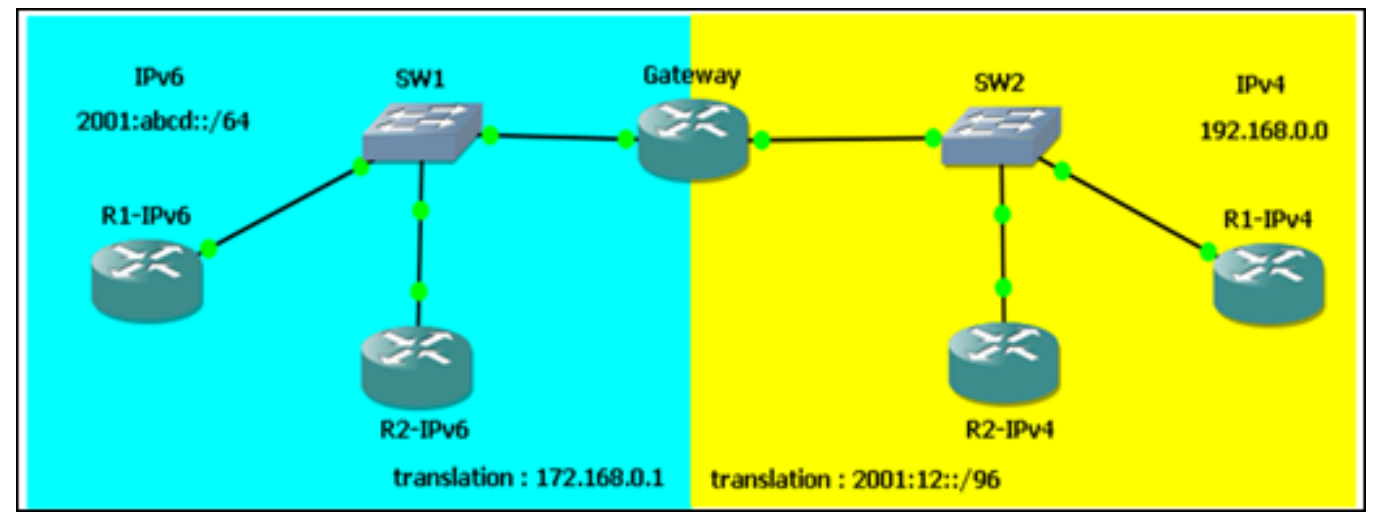

Gambar 11. Jaringan Translation IPv6

\subsubsection{Hasil Uji Koneksi}

Hasil pengujian menggunakan perintah ping seperti pada Tabel 5 untuk pengujian dengan protokol IPv6. Pada Table 5 memperlihatkan bahwa perangkat router telah terhubung dengan jeda waktu rata - rata selama 74 ms dari R1-IPv6 menuju R2-IPv4.

Tabel 5. Hasil ping R1-IPv6 Menuju R2-IPv4

\begin{tabular}{|c|c|c|c|}
\hline \multirow{2}{*}{ Percobaan } & \multicolumn{3}{|c|}{ Waktu $(m s)$} \\
\cline { 2 - 4 } & Min & Avg & Max \\
\hline 1 & 56 & 72 & 100 \\
\hline 2 & 48 & 64 & 92 \\
\hline 3 & 48 & 87 & 204 \\
\hline
\end{tabular}

\subsubsection{Informasi Paket Data}

Dari hasil percobaan, paket data yang dikirim menggunakan protokol IPv6 memiliki ukuran 114 byte. Paket data ini dikirimkan dengan proses routing IPv6 dari perangkat R1IPv6 menuju port fastEthernet 0/0 demgan IP address 2001:abcd::1. Kemudian saat diterima oleh gateway, maka router tersebut akan membandingkan informasi dari paket data yang diterima. Jikalau IP address tercantum pada Tabel NAT, maka router akan mengubah header dan IP address (IPv6) dari paket data tersebut untuk disesuaikan dengan IP address yang lain (IPv4) dengan ukuran 94 byte. Setelah itu paket data yang telah dirubah akan 
diteruskan oleh gateway menunjukkan router R2-IPv4 dengan protokol IPv4. Terdapat perubahan header IPv6 dengan ukuran 40 byte yang diganti menjadi header IPv4 dengan ukuran 20 byte. Proses translasi ini diatur oleh router gateway yang memiliki daftar Tabel NAT berisi IP address dari perangkat dengan IPv4 ke IPv6 dan sebaliknya untuk perangkat IPv6 ke IPv4.

Dengan seluruh data yang ada telah menunjukkan bahwa metode translation memungkinkan agar perangkat IPv6 dapat tetap terhubung dengan perangkat IPv4. Hal ini dapat terjadi karena adanya proses translasi yang dilakukan oleh router gateway, dimana adanya tabel khusus yang akan menjadi patokan bagi paket data yang akan dilewatkan kepada perangkat yang berbeda protokol.

\section{Kesimpulan}

Berdasarkan perancangan, perealisasian dan pengujian dapat di tarik kesimpulan bahwa metode dual stack dapat menggabungkan perangkat dengan protokol IPv4 dan IPv6 dalam jaringan yang sama, namun hanya dapat terhubung dengan protokol yang sama. Metode tunneling merupakan proses enkapsulasi dan dekapsulasi paket data. Metode ini diterapkan pada jaringan utama dengan protokol IPv4 sehingga mampu menghubungkan antar perangkat dengan protokol IPv6, dimana paket data IPv6 yang akan melewati jaringan utama akan ditambah dengan protokol IPv4. Metode translation dapat menghubungkan perangkat dalam satu jaringan dengan protokol yang berbeda. Hal ini dapat terjadi karena adanya proses translasi pada paket data, sehingga dapat diterima oleh perangkat dengan protokol yang berbeda.

\section{Daftar Pustaka}

[1] Davies J. 2012. Understanding IPv6. Microsoft Corporation; New York.

[2] Silvia H. 2014. IPv6 Essentials Third Edition. O'Reilly.

[3] Lestari Indah, Renny, Agustus 2011, “Menganalisa Kinerja Antara Metode Tunneling 6to4 Dengan Metode Dual Stack Berbasis Protokol IPv6 Menggunakan Router Mikrotik", repository.amikom.ac.id/files/Publikasi_07.11.1568.pdf, 5 Januari 201

[4] GAO. 2006. Federal Agencies Need to Plan for Transition and Manage Security Risks. United States Government Accountability Office.

[5] Babatunde O, Al-Debagy O. 2014. A Comparative Review Of Internet Protocol Version 4 (IPv4) and Internet Protocol Version 6 (IPv6). International Journal of Computer Trends and Technology (IJCTI). Vol 13 (1): 10-13

[6] Joshua Marthen Manuputty, Penyusunan Pedoman Praktikum Untuk Mata Kuliah Jaringan Komputer dengan Mengimplementasikan Teknologi IPV6, Skripsi Fakultas Teknik Elektronika dan Komputer Universitas Kristen Satya Wacana, 2015. 
